\title{
BMJ Open Epidemiology and risk factors of pesticide poisoning in Malaysia: a retrospective analysis by the National Poison Centre (NPC) from 2006 to 2015
}

\author{
Nur Azzalia Kamaruzaman (10 , ${ }^{1}$ Yin-Hui Leong, ${ }^{1}$ Mohd Hafiidz Jaafar, ${ }^{1,2}$ \\ Halilol Rahman Mohamed Khan, ${ }^{1}$ Noor Afiza Abdul Rani, ${ }^{1}$ Mohd Fadhli Razali, ${ }^{1}$ \\ Mohamed Isa Abdul Majid ${ }^{1}$
}

To cite: Kamaruzaman NA, Leong Y-H, Jaafar MH, et al. Epidemiology and risk factors of pesticide poisoning in Malaysia: a retrospective analysis by the National Poison Centre (NPC) from 2006 to 2015. BMJ Open 2020;10:e036048. doi:10.1136/ bmjopen-2019-036048

- Prepublication history for this paper is available online. To view these files, please visit the journal online (http://dx.doi org/10.1136/bmjopen-2019036048).

Received 28 November 2019 Revised 19 February 2020 Accepted 05 May 2020

Check for updates

(C) Author(s) (or their employer(s)) 2020. Re-use permitted under CC BY-NC. No commercial re-use. See rights and permissions. Published by BMJ.

${ }^{1}$ Malaysia National Poison Centre, Universiti Sains Malaysia, 11800 USM, Penang, Malaysia

${ }^{2}$ School of Industrial Technology, Universiti Sains Malaysia, 11800 USM, Penang, Malaysia

Correspondence to

Dr Nur Azzalia Kamaruzaman; azzalia@usm.my

\section{ABSTRACT}

Objective Pesticide poisoning is a global health problem, and its progressive deterioration is a major cause of concern. The objective of this study is to assess epidemiological characteristics and identify risk factors of pesticide poisoning in Malaysia.

Setting Pesticide poisoning database of Malaysia National Poison Centre (NPC) from 2006 to 2015.

Participants Telephone enquiries regarding pesticide poisoning were made by healthcare professionals. Information received by the NPC was entered into a retrievable database of standardised Poison Case Report Form, as adapted from the World Health Organization (WHO)

Outcomes The outcome of the study is to provide an overview of national epidemiological profile of pesticide poisoning. High-risk groups of people and their circumstances were also identified to ensure that appropriate measures are strategised.

Results Within the study period, a total of 11087 pesticide poisoning cases were recorded. Sixty per cent of these cases were intentional in nature and most were found among male individuals (57\%) of the Indian race (36.4\%) aged between 20 and 29 years $(25.5 \%)$, which occurred at home (90\%) through the route of ingestion $(94 \%)$. The highest number of poisoning was due to herbicides (44\%) followed by agricultural insecticides $(34 \%)$, rodenticides $(9.9 \%)$, household insecticides $(9.5 \%)$ and fungicides $(0.5 \%)$. In addition, $93.6 \%$ of intentional pesticide poisoning cases were caused by suicide attempts. The results of this study show that there was an increasing trend in pesticide poisoning incidents over the 10 -year duration. This indicates that pesticide poisoning is a prevalent public health problem in Malaysia, resulting in an average incidence rate of 3.8 per 100000 population. Conclusions Deliberate pesticide ingestion as a method of suicide has become a disturbing trend among Malaysians. Therefore, regulation of highly hazardous pesticides must be enforced to ensure controlled and limited access to these chemicals by the public.

\section{INTRODUCTION}

The World Health Organization (WHO) has identified pesticide poisoning as a leading
Strengths and limitations of this study

- The study provides a 10-year overview of pesticide poisoning incidents in Malaysia as reported to the National Poison Centre (NPC)

- Data shows types, modes, demographic patterns and incidence rates of poisoning cases as well as the identification of high-risk people and their circumstances.

- In this retrospective study, recall bias might have occurred from patients who recalled past exposures inaccurately.

- The data presented in this study may be underreported as reporting poisoning cases to the NPC are not mandatory in Malaysia.

- There was lack of information on the medical outcome of the patients, thereby restricting the study's scope of depth.

cause of public health problem which causes significant morbidity and mortality. ${ }^{1}$ Globally, death from deliberate ingestion of pesticides claimed more than 168000 lives every year, which accounted for $20 \%$ of all suicides, and the majority of these incidents were reported from developing countries. ${ }^{2-4}$ Moreover, the number of non-fatal cases of pesticide poisoning is expected to be much higher due to under-reported cases. ${ }^{5}$ Pesticides are divided into two groups, which are household pesticides and agricultural pesticides. The household pesticides consist of household insecticides and rodenticides while agricultural pesticides consist of various formulations of insecticides, herbicides and fungicides. In addition, pesticide-induced health problems can be categorised into intentional, accidental and occupational. ${ }^{56}$

Major pesticide use in Malaysia is attributed to the progressive agricultural development in the country, whereby farming practices 
involve the use of pesticides on various vegetables, fruits, paddy, rubber and palm oil plantations. ${ }^{6}$ As of 2016 , pesticide use in Malaysia reached at level of 49199.43 tonnes of active ingredients, with total use of $5.9 \mathrm{~kg} / \mathrm{ha}$ of crop land. Import value was estimated to be worth US $\$ 202572.48$ while the export value was worth at US\$68 424.65. ${ }^{7}$ As stated by the Malaysian Department of Agriculture, ${ }^{89}$ the use of pesticides in Malaysia is regulated, and the common pesticides used in agriculture are the organophosphates, the pyrethroids, glyphosate and 2,4-D-dimethylammonium. Some examples of organophosphates currently available in Malaysia are temephos (WHO class IV), chlorpyrifos (WHO class IV), dimethoate (WHO class II) and malathion (WHO class III). There are also some pesticides whose use is highly regulated such as paraquat (WHO class II), monocrotophos (WHO class Ia), chlorpyrifos (WHO class Ib) and methamidophos (WHO class $\mathrm{Ib}$ ) while highly toxic pesticides namely endosulfan (WHO class II) and methomyl (WHO class Ib) are banned.

Despite strict procedures in the production of pesticides and various methods to ensure negligible harmful effects to the well-being of humans, using pesticide as a mean of suicide still remains a universal approach. ${ }^{10}$ This may be contributed by widespread application of pesticide in agriculture as well as easy access to pesticide. ${ }^{11}$ In fact, suicide by pesticide is most prevalent in South Asia, South East Asia and China. ${ }^{3}$

A review of literature publications has shown the current existence of reports in Malaysia which investigated poisoning cases on a wider profile with analysis on specific poisoning agents, modes or demographic factors. ${ }^{12-14}$ However, it is apparent from the literature searches that there is a lack of study on specific types of poisoning namely pesticide poisoning. Therefore, this study aims to evaluate the magnitude of pesticide poisoning in Malaysia as an overview of national epidemiological trend. In addition, this research aims to identify high-risk individuals and provide scientific evidence to serve as a fundamental step in the development of preventive national strategies against this escalating situation.

\section{METHODS}

This study provides a retrospective review of pesticide poisoning cases referred for enquiries to the Malaysia National Poison Centre (NPC), from 1 January 2006 to 31 December 2015. Pesticide poisoning incidence in association with several sociodemographic factors, circumstances of occurrences, identification of implicated pesticides and other variables is also discussed.

\section{Data source}

The establishment of the first and only NPC in 1994 is a culmination of the Integrated Drug and Poison Information Service research activities since the $1980 \mathrm{~s}^{15}$ Its role as the sole poison information centre in Malaysia, which serves a population of over 28.3 million people, primarily involves providing toxicological information and consultation to healthcare professionals and the general public 24 hours a day, for 7 days a week. ${ }^{14} 15$ The poisoning and drug enquiries which make up 40006000 cases annually are mainly conducted via telephone calls and are handled by a team of nine specially trained in-house pharmacists.

\section{Data collection strategy}

All telephone calls made to the NPC were entered into a standardised Poison Case Report Form (PCRF), as adapted from the WHO. ${ }^{16}$ The retrievable web-based data entry was customised and used cloud management applications for data collection and storage, whereby face and content validation was previously established by academics and pharmacists in the centre. In addition, the calls were recorded in a voice logging and recording system so that audio could be retrieved for the future purposes of documentation, training and audit.

The enquiry details obtained included product/ poison information (chemical name), patient's age, sex, route and duration of exposure, mode and symptoms of poisoning, treatment already provided and other necessary queries related to the patient. Based on WHO INTOX classification, poisoning enquiries are classified as intentional, unintentional or adverse reaction. The definition of intentional incidence is 'an exposure by any route (or incident) where there was an intention to cause harm', an unintentional incidence is 'an exposure by any route (or incident) where there was no intention to cause harm' while adverse reaction is 'an unwanted effect of a drug, food or other agent occurring after the normal use of that agent'. ${ }^{17}$

As part of the protocol by NPC, when a call was made to the centre by a healthcare professional regarding a poisoning case, the caller was enquired if the case was originated from the hospital from where the call was made, or if the case was referred from another hospital. If the latter occurred, then the call was crosschecked with the first hospital, as to ensure that double counting was prevented during data collection.

\section{Inclusion and exclusion criteria}

For this study, data included were enquiry calls regarding pesticide incident cases. These telephone calls were made by healthcare professionals from hospitals across Malaysia between January 2006 and December 2015. Only complete information for PCRF entry was included in this study, so obtaining full enquiry details was important when the calls were made. All entries were complete and were recorded in the system.

Any pesticide exposure calls made by the general public were excluded from this study as these calls had insufficient information for a PCRF entry. Moreover, other general poisoning calls (non-pesticide cases) made by either healthcare providers or the public were excluded due to irrelevance to the purpose of the current study. 


\section{Statistical analysis}

Demographic characteristics of patients involved in pesticide poisoning and types of incidents were examined using descriptive analysis. In this study, the annual rates of pesticide were described as number of incident cases per 100000 population which were presented by gender and state. Data analysis was performed using PASW V.18.

\section{Patient and public involvement}

In this study, retrospective data were generated in the form of reported poisoning cases from hospitals in Malaysia. Healthcare professionals, who mainly consisted of medical doctors, referred pesticide poisoning cases to the NPC for consultancy and their enquiries were recorded by on-call pharmacists of the NPC. The NPC had no direct interaction with patients and medical doctors provided their patients' information to the NPC without any personal identifiers. Due to the NPC's recognised role by the Malaysian government as the only poison centre nationwide, both health professionals and the public were aware of the NPC's role as consultants and information providers as well as an avenue for data collection regarding poisoning cases in the country.

\section{RESULTS}

\section{Pesticide agents involved in poisoning}

Within the 10-year study period from 2006 to 2015, a total of 39088 poisoning calls were received by the NPC. From this total number, pesticide was the second largest classification of poison substances after pharmaceuticals at 11087 (28.4\%) whereas pharmaceuticals recorded 14081 cases $(36 \%)$. Other types of poisoning included household chemicals, substances of abuse, agricultural products, natural toxins, industrial and commercial products and so on. Forty-three calls were made by the public regarding pesticide poisoning, but these were nonhospitalised cases, so they were excluded in this study.

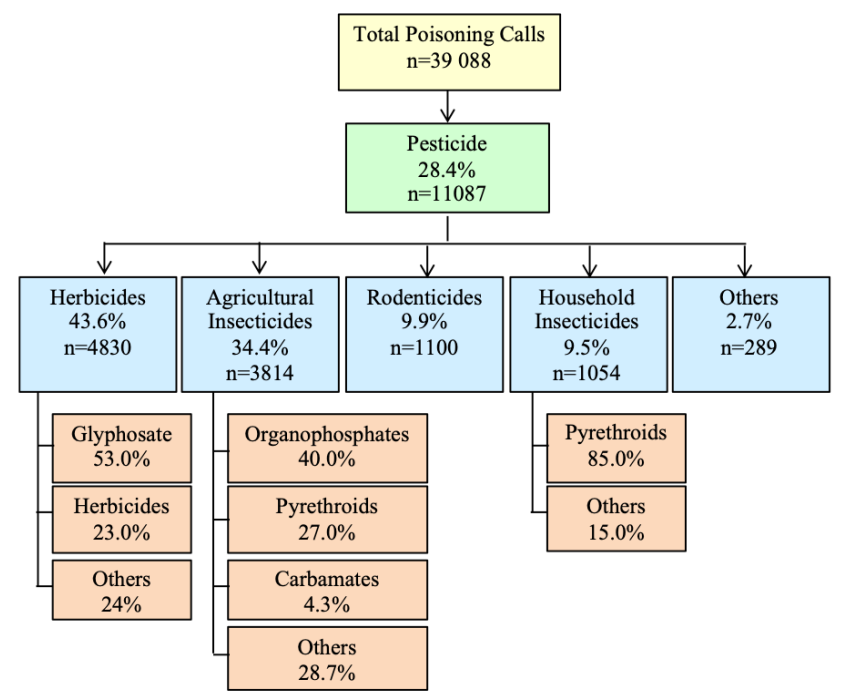

Figure 1 Types of pesticide poisoning.
Looking closely at pesticide data in figure 1 , the highest number of pesticide poisoning cases was caused by herbicides $(43.6 \%, \mathrm{n}=4830)$, followed by agricultural insecticides $(34.4 \%, \mathrm{n}=3814)$, rodenticides $(9.9 \% \mathrm{n}=1100)$ and household insecticides $(9.5 \%, \mathrm{n}=1054)$. In greater detail, among the herbicides, the highest poisoning cases recorded were due to glyphosate $(53 \%, \mathrm{n}=2506)$ and paraquat $(23 \%, \mathrm{n}=1063)$. Of the different types of agricultural insecticides, $40 \%$ of the poisoning cases came from organophosphates, and other poisoning cases were caused by pyrethroids (27\%, $\mathrm{n}=1208)$ and carbamates $(4.3 \%, \mathrm{n}=165)$. However, pyrethoids made up about $85 \%$ of poisoning cases for the household insecticides. Among the organophosphate agents, chlorpyrifos $(n=737)$ was recorded to be the top agent involved with poisoning and followed by malathion $(n=474)$.

\section{Sociodemographic characteristics}

The general patterns of demographic characteristics of patients involved in pesticide poisoning are demonstrated in table 1 . The results showed that pesticide poisoning was more prevalent in men $(57.2 \%, \mathrm{n}=6342)$ compared with women. Across different races in Malaysia, a larger number of intentional pesticide poisoning were reported among the Indian race $(34.6 \%, \mathrm{n}=3836)$, with the Malay race $(20.4 \%, \mathrm{n}=2265)$ recording the second highest. For distribution among age groups, the highest incidence rate was observed among those of 20-29 years (25.5\%, $\mathrm{n}=2825)$ and followed by those who aged between 30 and 39 years $(19.1 \%, \mathrm{n}=2117)$. Geographical distribution showed that most pesticide poisoning cases were most prevalent in the states of Perak $(17.9 \%, \mathrm{n}=1990)$ and Selangor $(17.6 \%, \mathrm{n}=1953)$, which are located in the west peninsular of Malaysia. The majority of exposures were acute at $99 \%$, with ingestion being the predominant route of exposure at $93.9 \%(\mathrm{n}=10406)$, followed by inhalation (4.1\%, $\mathrm{n}=449)$, cutaneous $(1.2 \%, \mathrm{n}=134)$ and ocular exposure $(0.6 \%, \mathrm{n}=62)$. More than $90 \%(\mathrm{n}=10101)$ of the poisoning cases were reported to have occurred at home and a limited number of cases were reported to have occurred at the workplace $(4.3 \%, \mathrm{n}=482)$, whereby the majority $(90 \%, \mathrm{n}=451)$ of occupational induced poisoning cases were reported to have occurred in the agricultural area.

\section{Relative importance of types of pesticide poisoning}

Based on table 2, most of the pesticide poisoning incidents occurred intentionally $(60.1 \%, \mathrm{n}=6669)$, with suicides recording the highest type of incidents in this category at $93.6 \%(n=6368)$. On the other hand, unintentional poisoning which made up $37.8 \%(n=4196)$ of all pesticide poisoning incidents reported accidental as the highest type of incidents at $91.8 \%(\mathrm{n}=3854)$ with occupational incidents reported second highest at $5.2 \%(\mathrm{n}=218)$.

\section{Pesticide poisoning incidence rates}

As illustrated in figure 2, during the decade long study period, analysis showed an increasing trend in pesticide 
Table 1 Sociodemographic characteristics of patients with pesticide poisoning

Sociodemographic characteristics n (\%)

\begin{tabular}{|c|c|c|c|}
\hline Gender & $(n=9924)$ & Type of exposure & $(n=11031)$ \\
\hline Male & $6342(57.2)$ & Acute & $10983(99.1)$ \\
\hline Female & 3582 (32.3) & Chronic & $28(0.3)$ \\
\hline Race & $(n=8655)$ & Acute on chronic & $20(0.2)$ \\
\hline Indian & 3836 (34.6) & Route of exposure & $(n=11064)$ \\
\hline Malay & 2265 (20.4) & Ingestion & $10406(93.9)$ \\
\hline Chinese & $1089(9.8)$ & Inhalation & $449(4.1)$ \\
\hline Others & $1243(11.2)$ & Cutaneous & $134(1.2)$ \\
\hline Non-Malaysian & $222(2.0)$ & Ocular & $62(0.6)$ \\
\hline Age group (years) & $(n=11087)$ & Mucosal & $9(0.1)$ \\
\hline $0-4$ & $1221(11.0)$ & Injection & $3(0.0)$ \\
\hline $5-9$ & $147(1.3)$ & Others & $1(0.0)$ \\
\hline $10-14$ & $232(2.1)$ & Location of incident & $(n=10661)$ \\
\hline $15-19$ & $1044(9.4)$ & Home & $10101(91.1)$ \\
\hline $20-29$ & 2825 (25.5) & Workplace & $482(4.3)$ \\
\hline $30-39$ & 2117 (19.1) & Open place & $35(0.3)$ \\
\hline $40-49$ & $1206(10.9)$ & Hospital/clinics & $17(0.2)$ \\
\hline $50-59$ & $632(5.7)$ & Enclosed public place & $11(0.1)$ \\
\hline$>60$ & $535(4.8)$ & Academic institution & $6(0.1)$ \\
\hline Unclassified adult & 947 (8.5) & Nursing home & $2(0.0)$ \\
\hline Unclassified children & $27(0.1)$ & Institution (prison) & $2(0.0)$ \\
\hline Unrecorded & $174(1.6)$ & Other & $5(0.0)$ \\
\hline State & $(n=10941)$ & & \\
\hline Perak & $1990(17.9)$ & & \\
\hline Selangor & $1953(17.6)$ & & \\
\hline Johor & $1066(9.6)$ & & \\
\hline Negeri Sembilan & $1053(9.5)$ & & \\
\hline Pahang & $981(8.8)$ & & \\
\hline Sabah & $838(7.6)$ & & \\
\hline FT Kuala Lumpur & $695(6.3)$ & & \\
\hline Sarawak & 606 (5.5) & & \\
\hline Kedah & $566(5.1)$ & & \\
\hline Pulau Pinang & $517(4.7)$ & & \\
\hline Melaka & $312(2.8)$ & & \\
\hline Kelantan & 177 (1.6) & & \\
\hline Terengganu & $80(0.7)$ & & \\
\hline FT Putrajaya & $72(0.6)$ & & \\
\hline Perlis & $29(0.3)$ & & \\
\hline FT Labuan & $6(0.1)$ & & \\
\hline
\end{tabular}

FT, Federal Territory

poisoning incidents, with an estimated average incidence rate of 3.8 per 100000 population. Pesticide poisoning was more prevalent in males, with an average incidence rate of 4.21 per 100000 population as compared with females with an incidence rate of 2.54 per 100000 population.

For distribution among age groups as depicted in table 3 , the highest incidence was observed among those 
Table 2 Types of pesticide poisoning incidents

\begin{tabular}{lc}
\hline Incident category & $\mathbf{n}(\%)$ \\
\hline Intentional & $6669(60.1)$ \\
\hline Unintentional & $4196(37.8)$ \\
Adverse reaction & $31(0.3)$ \\
\hline Others & $191(1.7)$ \\
\hline Type of incident (intentional) & $\mathrm{n}=6669$ \\
\hline Suicidal & $6328(93.6)$ \\
Abortion & $5(0.1)$ \\
Abuse & $10(0.1)$ \\
\hline Others & $51(0.8)$ \\
Unknown & $314(4.7)$ \\
Misuse & $50(0.7)$ \\
\hline
\end{tabular}

aged 20-29 years with an incidence rate of 4.88 per 100000 followed very closely by those who aged between 30 and 39 years with a rate of 4.87 per 100000 and children aged between 0 and 4 years, with an incidence rate of 4.8 per 100000 per population.

\section{DISCUSSION}

In Malaysia, pesticide poisoning is the second largest group of poisoning after pharmaceuticals. Herbicides caused the highest number of poisoning by $44 \%$, and from this category, glyphosate was the main contributing agent $(53 \%)$ and this was followed by paraquat $(23 \%)$. These findings were supported by the American Association of Poison Control Centres in year 2015 which proved that glyphosate and paraquat were found to be the most used herbicides in induced poisoning cases in the country. ${ }^{18}$ South Korea also reported herbicides to be most commonly used as a suicide agent whereby paraquat was ranked the highest between 2006 and 2010. ${ }^{19}$ Following herbicides, agricultural insecticides were the second most common pesticide involved in pesticide poisoning incidents at $34 \%$, and of this total, organophosphates ranked the top at $40 \%$. These data are further supported by published literature which stated that this type of pesticide has been reported to be the primary cause of pesticide poisoning in many Asian countries. ${ }^{10} 20$

Malaysia is a country of diverse ethnicities, with Malays being the largest ethnic group, and Chinese and Indians being the second and third largest ethnic groups, respectively. Other races include a myriad of indigenous ethnic groups which make up the minority of the population. ${ }^{21}$ In Malaysia, incidence and patterns of suicide are attributed by cultural, religious, social and even political factors. Looking at the characteristics of demography in table 1, males $(57.2 \%)$ of Indian descent $(34.6 \%)$ between the ages of 20 and $29(25.5 \%)$ have recorded the highest involvement in pesticide poisoning incidents. Preponderance of males as found in the current study is corroborated by other pesticide poisoning studies. ${ }^{12} 19$ Contributing factor could be largely attributed to financial burden, family disharmony and stress. Despite being the smallest of the three main races in Malaysia, Indians recorded the highest number of pesticide poisoning cases. This finding is supported by other local studies and some factors could be linked to the Indians, namely poverty, alcoholism, psychiatry morbidity, caste issues, other social distress, cultural and religious factors and attitude to suicide. ${ }^{22}{ }^{23}$ Malays on the other hand, though remain the major race in the country, have lower suicide

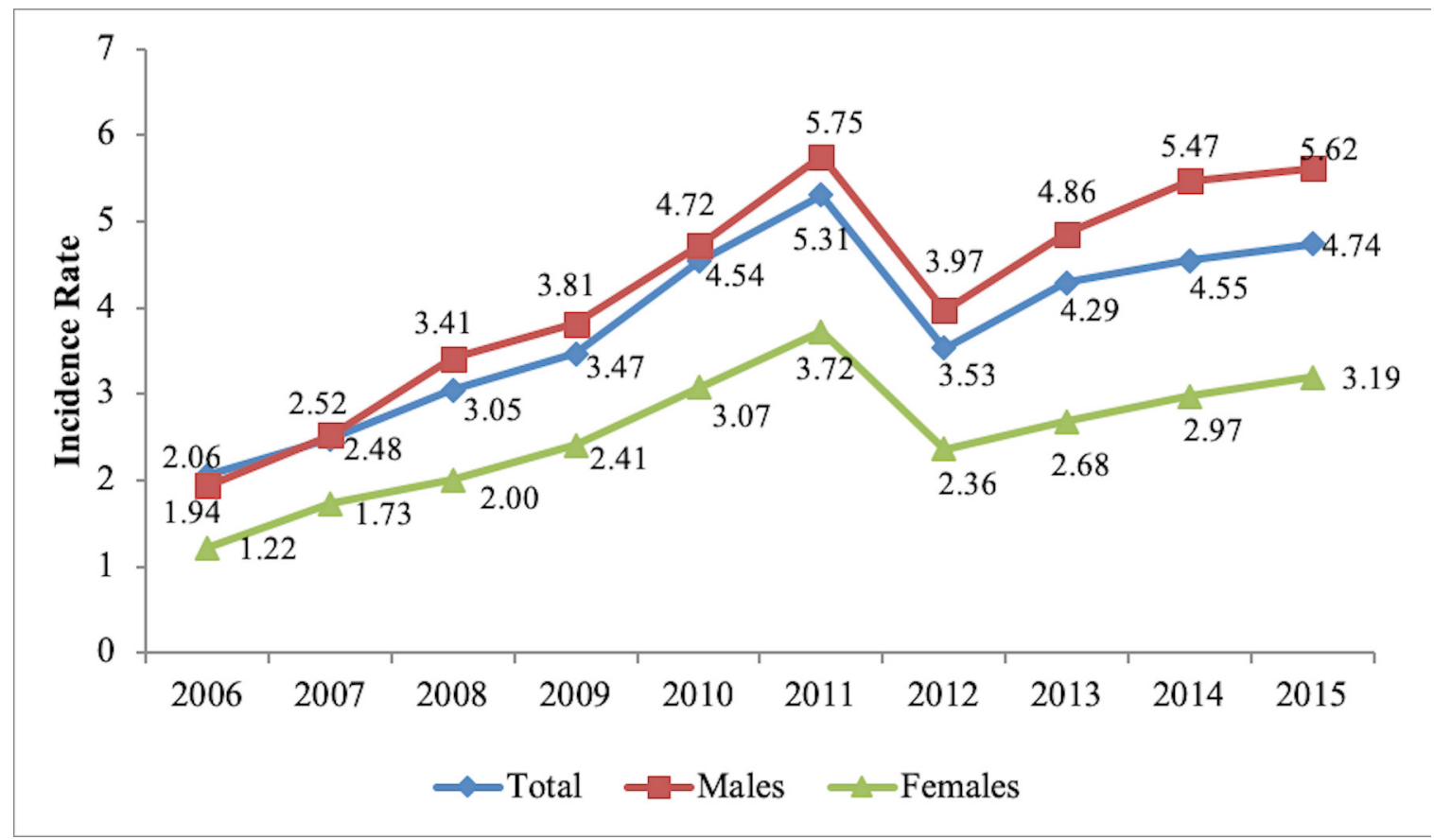

Figure 2 Gender-based pesticide poisoning incidence rate (per 100000 population). 
Table 3 Pesticide poisoning incidence rates according to age groups (per 100000 population)

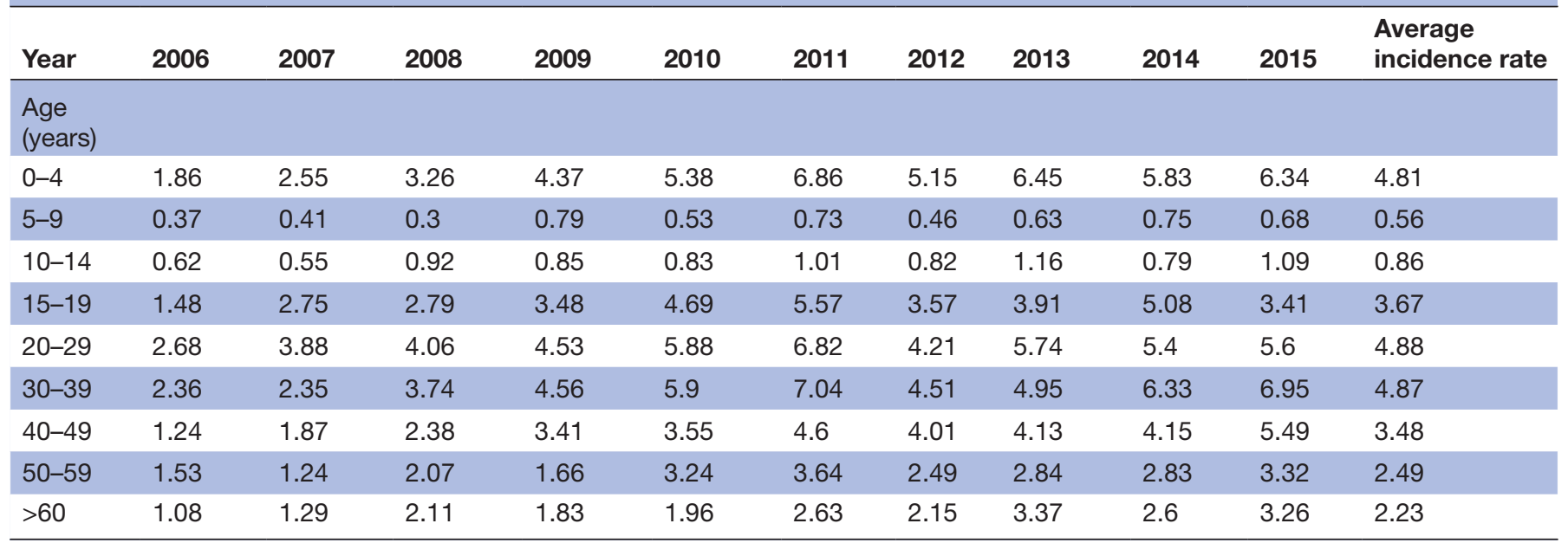

attempts as the Malays practice Islam, a religion which forbids suicide. ${ }^{12}$

Population between the ages 20-29 and 30-39 have shown to be most affected with pesticide poisoning at $25.5 \%$ and $19.1 \%$, respectively. This finding is supported by Peshin et $a l^{24}$ who found that people who were most susceptible to pesticide poisoning aged between 18 and 35 , and a few South-Asia-based studies also further confirmed our findings. ${ }^{12}$ It has been reported that people from this similar age range in particular deal with higher stress levels in comparison to other age groups. These are early career beginners who deal with psychoemotional problems involving unemployment, economic hardship, family pressure and so on. Subsequently, they are afflicted with depression or face with negative perceptions of life, putting them in a higher probability to have suicide attempts. $^{25-27}$

Malaysia is a federation consisting of 13 states and 3 federal territories. ${ }^{28}$ The occurrences of poisoning were reported to be the highest in the states of Perak and Selangor in comparison to other states in Malaysia with around $18 \%$ each. Even though Perak and Selangor are urban and economically developed, these two states have extensive palm oil plantations as Malaysia is the second major exporter of palm oil in the world..$^{29-31}$ Therefore, pesticide is an essential element to productive growth of palm oil trees. In addition, Malaysia whose economy depends highly on other agricultural developments relies heavily on utilisation of pesticide in its farms. ${ }^{31}$ Thus, the workers, most of which are Indians residing in the rural agricultural areas, are exposed to pesticides on a daily basis, and this could be a factor which triggers suicide tendencies. $^{32}$

Of the total number of poisoning cases, $99 \%$ were caused by acute exposure, and $94 \%$ were exposed to poisoning via ingestion. In addition, $91 \%$ of cases occurred at home. Moreover, more than half $(60 \%)$ of all poisoning cases were intentional and $94 \%$ of these cases were suicidal in nature. Previous reports have indicated that increased suicide attempts were contributed by easy availability and accessibility of pesticides. ${ }^{33-35}$ In fact, in China, it has been reported that those with no intention to commit suicide might be triggered with suicide thoughts by the availability of pesticides. ${ }^{31}$ These data are parallel with reports from the WHO which found that using agricultural pesticides as a mode of self-poisoning is the major contributor to the global burden of suicide and this trend is particularly prevalent in Asia. ${ }^{3} 32$

Looking at the types of poisoning incidents, the second most common type of poisoning is unintentional incidents, whereby almost $92 \%$ of these were accidental. Most of the cases occurred at home $(n=4196)$, and children below the age of 4 years old were the biggest group involved. This finding is troubling as children have higher susceptibility to chemical toxicity due to immaturity of their organ systems in detoxifying poison as well as greater body surface which could cause fast rate of absorption through the skin. Children also tend to have more skin exposed and more cuts, abrasions and rashes than adults, and this could easily lead to increased dermal absorption as a proportion of body weight. ${ }^{36}$ The major cause of children's accidental poisoning is a combination of children's (especially toddlers') curiosity and exploratory nature who tend to eat or lick everything as well as parents' and caretakers' casual handling and storage of pesticides which are within reach of the children. ${ }^{25}$

Our current study also reported that only $5 \%$ of unintentional poisoning cases were due to occupational negligence. However, studies have shown that most occupational poisoning cases were under-reported as the cases were either not presented to healthcare facilities or that cases presented were incorrectly recorded. ${ }^{36}$ Even in other agriculture-based developing countries, the proportion of acute pesticide poisoning arising from occupational exposure was very low when compared with the use of pesticides for intended self-harm, ${ }^{3738}$ and this supported the findings of the current study. This is also in agreement with a South African study which demonstrated that occupational poisoning cases were hugely under-reported as compared with suicides. ${ }^{39}$ Moreover, 
our study suggested that $80 \%$ of men were involved in occupational poisoning. This is expected in Malaysia where men are more commonly involved in the agricultural industry than women, thus enabling more access to pesticides.

In Malaysia, the average incidence rate of pesticide poisoning which is 3.8 per 100000 population is considered lower than the rate of other developing countries such as Sri Lanka and Central America (El Salvador and Nicaragua) at 180 and 35 per 100000 population, respectively. ${ }^{40}$ However, the increasing incidence rate of pesticide poisoning cases for the decade between 2006 and 2015 proved that this issue is not improving and is progressively deteriorating. The pesticide poisoning incidence has steadily increased from 2006, with a drop in 2012 and followed by an increasing trend till 2015. In addition, our findings which showed that pesticide poisoning in relation to men and women at ratio 2:1 corresponds with the national statistics reporting higher ratio of men showing suicide tendencies than women. ${ }^{41}$

Suicide by self-poisoning of pesticide is a global health issue, and therefore must be addressed with effective community and government interventions. Countries namely China, India and Sri Lanka which reported serious cases of intentional and unintentional pesticide poisoning recognised the urgent need for action and addressed the issue through community engagement. While China implemented combining household lockboxes with community education about suicide prevention, India implemented central communal storage of pesticides and Sri Lanka implemented safely securing pesticides within households. The findings of these projects were optimistic, with participants finding the methods useful and acceptable, having greater awareness regarding risks of pesticide storage at home, and the countries recorded substantial drop in suicidal behaviours. ${ }^{42}$ In addition, government intervention has also proven to be effective as countries namely Sri Lanka, Bangladesh, South Korea, Taiwan and Japan have implemented national bans on highly hazardous pesticides (WHO class I) which are commonly ingested in acts of self-poisoning. This action resulted in an immediate decline in pesticide-poisoning suicides as well as overall suicide mortality rate. ${ }^{43-46}$ Therefore, it could be postulated that reduced access to highly hazardous pesticides is associated with a reduction in national suicide rate, and a worldwide ban on these chemicals can prevent tens of thousands of deaths every year.

As the sole poison centre in Malaysia, wealth of information is received from a nationally representative sample. The data have been assessed, analysed and recorded with appropriate protocol, with the acknowledgement of some inevitable limitations. Due to the retrospective nature of this study, recall bias might be a limitation whereby inaccuracy might have occurred in the ability of patients to recall past exposures accurately. Since researchers of the study have no control over exposures, it was solely dependent on patients to provide information on their exposure to pesticides. In addition, the actual number of pesticide poisoning cases as presented in this study may be underreported, as reporting to the NPC is not mandatory in Malaysia. Moreover, such cases may not be reported to the NPC by the healthcare providers if they deemed that the cases were treatable and they did not require assistance in the form of information on the management and treatment of pesticide poisoning cases. Another important limitation worth noting is the lack of information on the medical outcome of the patients after calls were made to the NPC. This information may provide us with an insight into the very depth of the problem, and subsequent appropriate action can be taken to remedy such problem. For example, fatal intoxication cases can bring forth some regulatory implementation strategies regarding pesticide use in Malaysia. Therefore, initiatives have been made to include this information for future use.

Even though Malaysia imposed certain restrictions on the use of certain pesticides such as glyphosate and paraquat under its Pesticides Act $1974,{ }^{47}$ lack of stricter and more assertive regulations enabled certain highrisk individuals to have access to these pesticides. Since easy availability of pesticides may convert a number of impulsive acts into suicide by means of pesticide ingestion, Malaysia should prioritise on better strategies for the regulation of pesticide use. In the meantime, the government of Malaysia will impose stricter importation of glyphosate and a total ban of paraquat by $2020 .{ }^{48}$ Moreover, providing information regarding proper pesticide storage and handling must be a national priority. The government must also focus on improving the nation's mental health and invest to provide tremendous support in various forms to those suffering in silence.

\section{CONCLUSIONS}

The upward trend of pesticide poisoning between 2006 and 2015 revealed that pesticide poisoning is a prevalent public health problem in Malaysia. Younger male adults had higher tendencies to resort to pesticide as a mode of suicide attempt, whereby the high-risk individuals were mostly of Indian descent. Major factors which caused the high rate of pesticide poisoning in Malaysia were suggested to be easy access to pesticide and lack of suicide awareness and education among Malaysians. Therefore, intensive intervention efforts, such as prevention efforts directed at controlling suicide, and mental health programmes for the vulnerable groups, proper enforcement and governing system on the use of pesticides, are needed to reduce the burden of pesticide poisoning in Malaysia.

Acknowledgements Special thanks go to the staff of the Malaysia National Poison Centre who contributed to this report, especially to the pharmacists who managed calls to the centre daily; Adilah Mohamed Ariff, Asdariah Misnan, Mahiya Nabilla Rosaria Abdul Hamid, Nur Afni Amir, Sulastri Sazaroni Md. Rashid and Sulastri Samsudin (HRMK, IAM and MFR who are also pharmacists are listed as coauthors in this paper). Last but not least, the authors would like to thank medical doctors 
in Malaysia for referring to the NPC for poisoning enquiries and subsequently providing data for the preparation of this manuscript.

Contributors HRMK and IAM designed the study while HRMK and MFR conducted data collection and entry with subsequent data analysis by NAAR. HRMK prepared the initial draft of the manuscript, and NAK, Y-HL and MHJ revised the draft. The finalised version of the manuscript was prepared by NAK and all authors reviewed the final manuscript prior to submission.

Funding The authors have not declared a specific grant for this research from any funding agency in the public, commercial or not-for-profit sectors.

Competing interests None declared.

Patient and public involvement Patients and/or the public were involved in the design, or conduct, or reporting, or dissemination plans of this research. Refer to the Methods section for further details.

\section{Patient consent for publication Not required}

Ethics approval The current study used secondary data analysis. The data received through medical doctors contained no information about the identities of the patients to ensure anonymity, and there was no potential for the anonymised data to become identifiable. With this justification, full ethical review was unnecessary.

\section{Provenance and peer review Not commissioned; externally peer reviewed.}

Data availability statement № data are available. No additional data available.

Open access This is an open access article distributed in accordance with the Creative Commons Attribution Non Commercial (CC BY-NC 4.0) license, which permits others to distribute, remix, adapt, build upon this work non-commercially, and license their derivative works on different terms, provided the original work is properly cited, appropriate credit is given, any changes made indicated, and the use is non-commercial. See: http://creativecommons.org/licenses/by-nc/4.0/.

\section{ORCID iD}

Nur Azzalia Kamaruzaman http://orcid.org/0000-0002-6846-1642

\section{REFERENCES}

1 Bertolote JM, Fleischmann A, Butchart A, et al. Suicide, suicide attempts and pesticides: a major hidden public health problem. Bull World Health Organ 2006;84:260.

2 Gunnell D, Eddleston M, Phillips MR, et al. The global distribution of fatal pesticide self-poisoning: systematic review. BMC Public Health 2007;7:357.

3 Mew EJ, Padmanathan P, Konradsen F, et al. The global burden of fatal self-poisoning with pesticides 2006-15: systematic review. J Affect Disord 2017;219:93-104.

4 World Health Organization. Suicide key facts [Internet]. Geneva: World Health Organization, 2019. Available: https://www.who.int/ news-room/fact-sheets/detail/suicide [Accessed 1 Oct 2019].

5 Litchfield $\mathrm{MH}$. Estimates of acute pesticide poisoning in agricultural workers in less developed countries. Toxicol Rev 2005;24:271-8.

6 Bakar BB. The Malaysian agricultural industry in the new millennium: issues and challenges. In: Basri $\mathrm{H}$, Mitkees $\mathrm{H}$, eds. Malaysia in global perspective. Egypt: University of Cairo Press, 2009: 275-310.

7 Knoema. Malaysia - Pesticide regulation [Internet]. VA USA: Knoema Corporation, 2019. Available: https://knoema.com/search?query= malaysia\%20pesticide\&source=HomePage [Accessed 1 Oct 2019].

8 Department of Agriculture. List of banned and restricted pesticide database (Updated 17/02/2020) [Internet]. Putrajaya: Department of Agriculture, 2020. Available: http://www.doa.gov.my/index/ resources/aktiviti_sumber/sumber_awam/maklumat_racun_perosak/ pendaftaran_rmp/senarai_racun_perosak_haram_terhad.pdf [Accessed 14 Feb 2020].

9 Department of Agriculture. List of registered pesticides (Updated 17/02/2020) [Internet]. Putrajaya: Department of Agriculture, 2020. Available: http://www.doa.gov.my/index.php/pages/view/388?mid= 235 [Accessed 14 Feb 2020].

10 Damalas CA, Eleftherohorinos IG, exposure P. Pesticide exposure, safety issues, and risk assessment indicators. Int $J$ Environ Res Public Health 2011;8:1402-19.

11 Eddleston M, Karalliedde L, Buckley N, et al. Pesticide poisoning in the developing world--a minimum pesticides list. Lancet 2002;360:1163-7.

12 Leong Y-H, Ariff AM, Khan HRM, et al. Paraquat poisoning calls to the Malaysia national poison centre following its ban and subsequent restriction of the herbicide from 2004 to 2015. J Forensic Leg Med 2018;56:16-20.
13 Leong KH, Tan LLB, Mustafa AM. Contamination levels of selected organochlorine and organophosphate pesticides in the Selangor river, Malaysia between 2002 and 2003. Chemosphere 2007;66:1153-9.

14 Tangiisuran B, Jiva M, Ariff AM, et al. Evaluation of types of poisoning exposure calls managed by the Malaysia national poison centre (2006-2015): a retrospective review. BMJ Open 2018;8:e024162.

15 Malaysia National Poison Centre [Internet]. Penang: National Poison Centre, 2018. Available: http://www. prn. usm. my/ [Accessed 31 Mar 2019].

16 World Health Organization. The INTOX Data management system [Internet]. Geneva: World Health Organization, 2019. Available: https://www.who.int/ipcs/poisons/intox dms/en/ [Accessed 31 Mar 2019].

17 Anderson BD, Seung H, Klein-Schwartz W. Trends in types of calls managed by U.S. poison centers 2000-2015. Clin Toxicol 2018;56:640-5.

18 Mowry JB, Spyker DA, Brooks DE, et al. 2015 Annual Report of the American Association of Poison Control Centers' National Poison Data System (NPDS): 33rd Annual Report. Clin Toxicol 2016;54:924-1109.

19 Cha ES, Khang Y-H, Lee WJ. Mortality from and incidence of pesticide poisoning in South Korea: findings from national death and health utilization data between 2006 and 2010. PLoS One 2014;9:e95299.

20 Sarkar D, Shaheduzzaman M, Hossain MI, et al. Spectrum of acute pharmaceutical and chemical poisoning in northern Bangladesh. Asia Pac J Med Toxicol 2013;2:1-4.

21 Sinniah A, Maniam T, Oei TP, et al. Suicide attempts in Malaysia from the year 1969 to 2011. ScientificWorldJournal 2014;2014:1-13.

22 Department of Statistics Malaysia. Population distribution and basic demographic characteristic report 2010 (Updated: 05/08/2011) [Internet]. Putrajaya: Department of Statistics Malaysia, 2015. Available: https://www.dosm.gov.my/v1/index.php?r=column/ctheme\&menu_id= LOpheU43NWJwRWVSZkIWdzQ4TIhUUT09\&bul_id=MDMxdHZjWTk1 SjFzTzNkRXYzcVZjdz09 [Accessed 29 Apr 2019].

23 Maniam T. Why do Malaysian Asian Indians have high suicide rate. In: Vijayakumar L, ed. Suicide prevention: meeting the challenge together. Chennai: Orient Longman Limited, 2003: 198-213.

24 Peshin SS, Srivastava A, Halder N, et al. Pesticide poisoning trend analysis of 13 years: a retrospective study based on telephone calls at the National poisons information centre, all India Institute of medical sciences, new Delhi. J Forensic Leg Med 2014;22:57-61.

25 van der Hoek W, Konradsen F. Risk factors for acute pesticide poisoning in Sri Lanka. Trop Med Int Health 2005;10:589-96.

26 Phillips MR, Yang G, Zhang Y, et al. Risk factors for suicide in China: a national case-control psychological autopsy study. Lancet 2002;360:1728-36

27 Konradsen F, Hoek Wvander, Peiris P. Reaching for the bottle of pesticide--a cry for help. Self-inflicted poisonings in Sri Lanka. Soc Sci Med 2006;62:1710-9.

28 Mekhilef S, Saidur R, Safari A, et al. Biomass energy in Malaysia: current state and prospects. Renew Sust Energ Rev 2011;15:3360-70.

$29 \mathrm{CS} \mathrm{H}$. Urban governance and rapid urbanization issues in Malaysia. Int J Sustain Built Environ 2008;13:1-24.

30 Wahid MB. Overview of the Malaysian palm oil industry 2008 [Internet]. Selangor: Malaysian Palm Oil Council, 2009. Available: http://econ.mpob.gov.my/economy/Overview_2008_latest130109. htm [Accessed 30 Mar 2019].

31 Abdullah N, Sulaiman F. The oil palm wastes in Malaysia. In: Matovic MD, ed. Biomass now: sustainable growth and use. Canada: Intech, 2013: 75-100.

32 Kok LP. Suicidal behaviour in Singapore. In: Kok LP, Tseng W, eds. Suicidal behaviour in the Asia-Pacific region. Singapore: Singapore university press, 1992: 176-98.

33 Banerjee I, Tripathi SK, Roy AS, et al. Pesticide use pattern among farmers in a rural district of West Bengal, India. J Nat Sci Biol Med 2014;5:313.

34 Konradsen F. Acute pesticide poisoning--a global public health problem. Dan Med Bull 2007;54:58-9.

35 van der Hoek W, Konradsen F. Risk factors for acute pesticide poisoning in Sri Lanka. Trop Med Int Health 2005;10:589-96.

36 Behrman RE, Kliegman RM, Jenson HB. Nelson textbook of paediatrics. $16^{\text {th }}$ edn. Philadelphia: WB Saunders Co, 2000.

37 Henao S, Arbelaez MP. Epidemiologic situation of acute pesticide poisoning in central America, 1992-2000. Epidemiol Bull 2002;23:5-9. 
38 Murali R, Bhalla A, Singh D, et al. Acute pesticide poisoning: 15 years experience of a large north-west Indian Hospital. Clin Toxicol 2009;47:35-8.

39 London L, Myers JE, Nell V, et al. An investigation into neurologic and neurobehavioral effects of long-term agrichemical use among deciduous fruit farm workers in the Western Cape, South Africa. Environ Res 1997;73:132-45.

40 Thundiyil JG, Stober J, Besbelli N, et al. Acute pesticide poisoning: a proposed classification tool. Bull World Health Organ 2008;86:205-9.

41 Hayati AN, Kamarul AK. National suicide registry Malaysia (NSRM). Med J Malaysia 2008;63 Suppl C:50-4.

42 World Health Organization. Safer access to pesticides for suicide prevention. Experiences from community interventions [Internet]. Geneva: World Health Organization, 2016. Available: https://apps. who.int/iris/bitstream/handle/10665/246233/WHO-MSD-MER-16.3eng.pdf?sequence=1 [Accessed 16 Feb 2020].

43 Knipe DW, Chang S-S, Dawson A, et al. Correction: suicide prevention through means restriction: impact of the 2008-
2011 pesticide restrictions on suicide in Sri Lanka. PLoS One 2017;12:e0176750.

44 Chowdhury FR, Dewan G, Verma VR, et al. Bans of who class I pesticides in Bangladesh-suicide prevention without hampering agricultural output. Int J Epidemiol 2018;47:175-84.

45 Lee J-W, Hwang I-W, Kim J-W, et al. Common pesticides used in suicide attempts following the 2012 paraquat ban in Korea. $J$ Korean Med Sci 2015;30:1517-21.

46 Gunnell D, Knipe D, Chang S-S, et al. Prevention of suicide with regulations aimed at restricting access to highly hazardous pesticides: a systematic review of the International evidence. Lancet Glob Health 2017;5:e1026-37.

47 Pesticides Act 1974. Laws of Malaysia, act 1492015.

48 Ravindran D. PANAP welcomes immediate ban on glyphosate imports in Vietnam, paraquat total ban in Malaysia in 2020 [Internet]. Penang: PAN Asia Pacific, 2019. Available: https://panap.net/2019/03/ panap-welcomes-immediate-ban-on-glyphosate-imports-in-vietnamparaquat-total-ban-in-malaysia-in-2020/ [Accessed 5 Apr 2019]. 